\title{
Laurence- Moon- Bardet- Biedle Syndrome - A Case Report
}

\author{
Nathani MA ${ }^{1}$, Karan $\mathrm{S}^{2}$, Asadullah H Saberi ${ }^{3}$, Basith $\mathrm{SA}^{4}$ \\ ${ }^{1}$ Dr. Manisha Arif Nathani, MS (Ophthalmology), Associate Professor, Department of Ophthalmology, ${ }^{2}$ Dr. Siddharth \\ Karan, MS (Ophthalmology), Professor, Department of Ophthalmology, ${ }^{3}$ Dr. S S Asadullah H Saberi, PG student, \\ Department of Ophthalmology, ${ }^{4}$ Dr. Syed Abdul Basith, PG student, Department of Ophthalmology. All are affiliated to \\ Deccan College of Medical Sciences, Hyderabad. Telangana, India.
}

Address For Correspondence: Dr. Manisha Arif Nathani. Email id: manishnathani1971@gmail.com

\begin{abstract}
Laurence Moon Bardet Biedle syndrome is a rare, autosomal recessive genetic disorder. It has got wide spectrum of clinical features.Spastic paraplegia is predominant feature in Laurence Moon syndrome and polydactyly and obesity are predominant features in Bardet Biedle syndrome. Pigmentary retinal degeneration, mental retardation and hypogonadism are common to both. We report a case of 7 year old female who presented to us with complaints of night blindness. She showed all ocular features, most of the general features of Laurence Moon Bardet Biedl syndrome and a typical family history.
\end{abstract}

Keywords: Obesity, Polydactyly, Retinitis Pigmentosa

\section{Introduction}

Laurence Moon Bardet Biedle syndrome is an autosomal recessive disorder [1]. Occurrence is different in different parts of the world, most common in the region like Kuwait, where the incidence is 1 in 13500 due to consanguineous marriages [2]. Main features of syndrome are polydactyly, pigmentary retinal dystrophy, central obesity, mental retardation and hypogonadism [3]. Other features like deafness, short stature, congenital heart block, and neurological disorders are also seen.It has got poor prognosis. Quality of life and survival of patient depends on the severity of the condition and treatment provided.Since, this condition has variable clinical features, it is very important to diagnose it for proper management. Here, we present an interesting and rare case with this syndrome.

\section{Case Report}

A 7 years old female patient presented to us with complaint of dimness of vision particularly during evening. She was a full term normal delivery and her parents had a consanguineous marriage being $1^{\text {st }}$ cousins. Her parents and other siblings are normal but her cousin is having similar complaints. On examination, she has high myopia with BCVA 6/60 with -7.0 D Sphere in both eyes. She has alternate exotropia of 30 diopters, deep set eyes and flat nose. Her fundus is showing picture of early retinitis pigmentosa (Figure 1). She has a short stature and central obesity, umbilical hernia, 11 fingers and 12 toes (Figure 2 and 3), high arched palate (Figure 4) and delayed milestones like she started walking at the age of two and a half years. Other investigations like USG abdomen, ECG and Echocardiography, Liver function test and renal function tests are normal. With all of the above findings, the diagnosis of Laurence Moon Bardet Biedle syndrome was made. Patient was given corrective glasses and referred to paediatric surgeon for her umbilical hernia and polydactyly. Counselling was done for the parents about the genetic form and progressive nature of the condition.Early deaths because of undetected renal impairment are quite common, so regular follow up was recommended. 


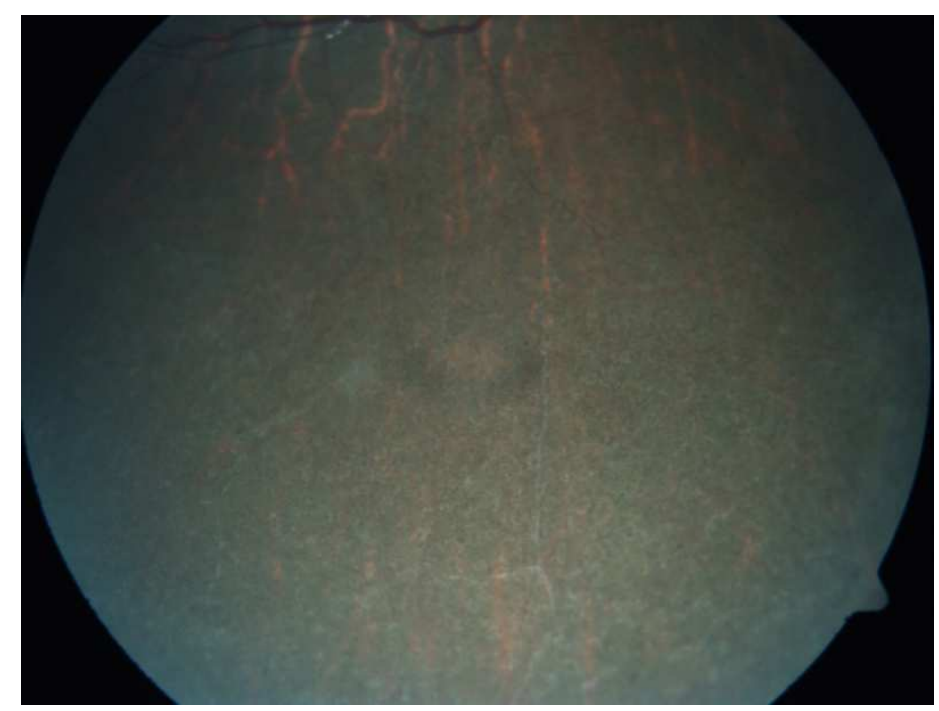

Figure 1: showing early picture of retinitis pigmentosa with autofluoroscence.

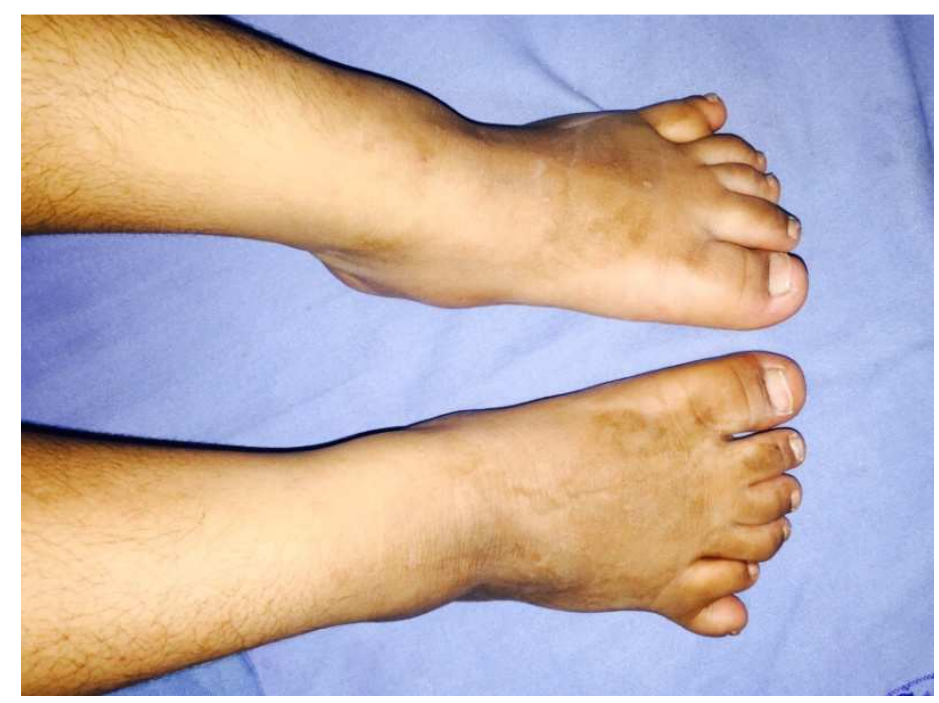

Figure 2: showing polydactyly in lower limbs

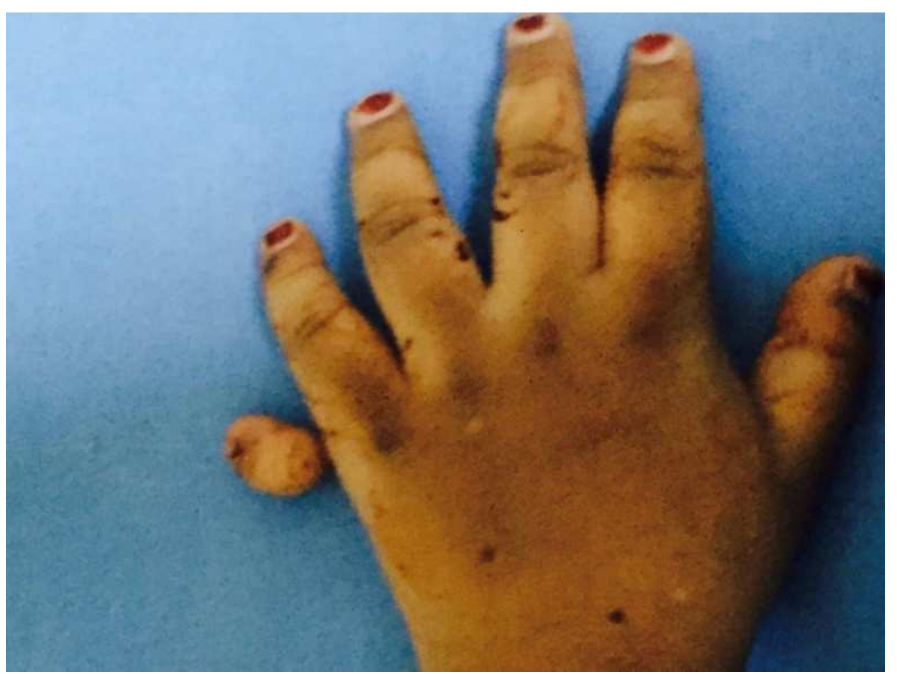


Figure 3: showing polydactyly in left hand.

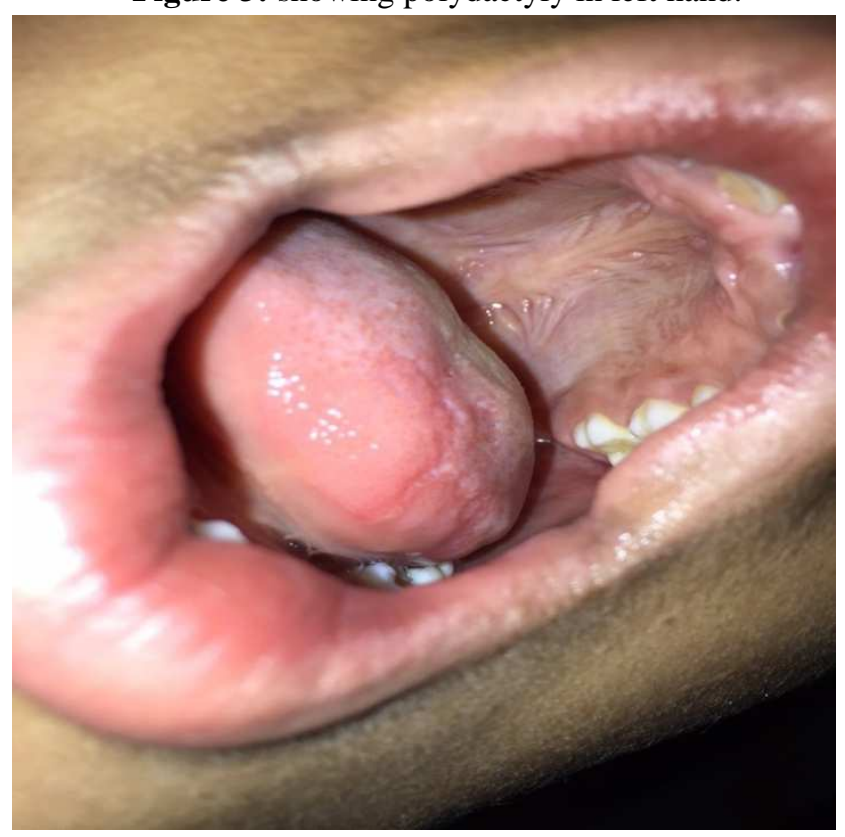

Figure 4: showing high arched palate.

\section{Discussion}

This syndrome was first described by Bardet and Biedle in 1920s. The prevalence is 1 in 160,000 in Europe but in the Arab communities of Kuwait it is 1 in 13,500 due to high consanguinity [2]. According to recent advances eleven genes are associated with this syndrome. They are BBS1, BBS2, ARL6/BBS3, BBS4, BBS5, MKKS/BBS6, BBS7, TTC8/BBS8, B1/BBS9, BBS10, and TRIM32/ BBS11 [4]. There is considerable variation in the extent and severity of the presentation, such as rapid loss of vision was reported by Batta et al [5] and pendular nystagmus reported by Qureshi et al[6]. Diagnosis can be made depending on the primary and secondary features suggested by Beales [7]. Primary features are Rod-cone dystrophy, Polydactyly, Obesity, Learning disabilities, Hypogonadism in males and renal anomalies. Secondary features are Speech disorder, Brachydactyly, Developmental delay, Polyuria/ polydipsia, Ataxia, Poor coordination/clumsiness, Diabetes mellitus, Left ventricular hypertrophy, Hepatic fibrosis and Spasticity. 4 of primary or 3 of primary and 2 of secondary features should be present for the diagnosis.This condition requires a team of appropriate specialities for proper planning and management so that the patient gets best treatment.

\section{Conclusion}

We report a typical case of LMBB syndrome in a 7 year old female patient with dimness of vision and night blindness with presence of retinitis pigmentosa,

polydactyly, obesity, umbilical hernia, exotropia, high myopia, deep set eyes, flat nose, high arched palate, delayed milestones, inter-related marriage of parents and a positive family history of similar complaints. The main purpose to present this case is to make reader aware of this condition. It is supposed to be a rare condition but it may be because of failure to diagnose incomplete presentations.

\section{Bibliography}

1. Sahu J; Jain V; Laurence-Moon-Bardet-Biedl Syndrome. J Nepal Med Assoc 2008;47(172):235-7.

2. Qureshi T; Ayub; Nasti A R; Ashai M; LaurenceMoon(Bardet) Biedle syndrome, JK-Practitioner 2003;10(3):217-218.

3. Rajasekhar P;Kumar M P; Aalekhya P S;Laurence Moon Bardet Biedle Syndrome - Case Report and Review of Literature. IJSR, Feb 2015;4(2);285-86.

4. Batta R, Mukharjee G. Laurence Moon Bardet Biedl Syndrome (A typical presentation). Indian $\mathrm{J}$ Ophthalmol. 1978 Apr;26(1):25-6. 
Case Report

5. Beales PL, Elcioglu N, Woolf AS, Parke D, Flinter FA. Newcriteria for improved diagnosis of Bardet-Biedl syndrome: results of a population survey. J Med Genet 1999;36(6):43746. 6. Kanski J, Bowing $\quad$ B, $\quad$ Clinical
ophthalmology;Saundera; 2013.

7. Ryan S, Retina;Saunders;2013.

\section{How to cite this article?}

Nathani MA, Karan S, Asadullah H Saberi, Basith SA. Laurence- Moon- Bardet- Biedle Syndrome - A Case Report. Int J Med Res Rev 2015;3(7):773-776. doi: 10.17511/ijmrr.2015.i7.140. 